\title{
Brancos, Pretos e o Outro que não existe: ensaio sobre a impossibilidade do diálogo em Branco: o cheiro do lírio e do formol
}

White, Black and the nonexistent Other: essay on the impossibility of dialogue in Branco: o cheiro do lírio e do formol

Ferdinando Martins Crepalde

Ferdinando Martins Crepalde Professor do Departamento de Comunicações e do PPGAC da Escola de Comunicações e Artes da Universidade de São Paulo (USP).

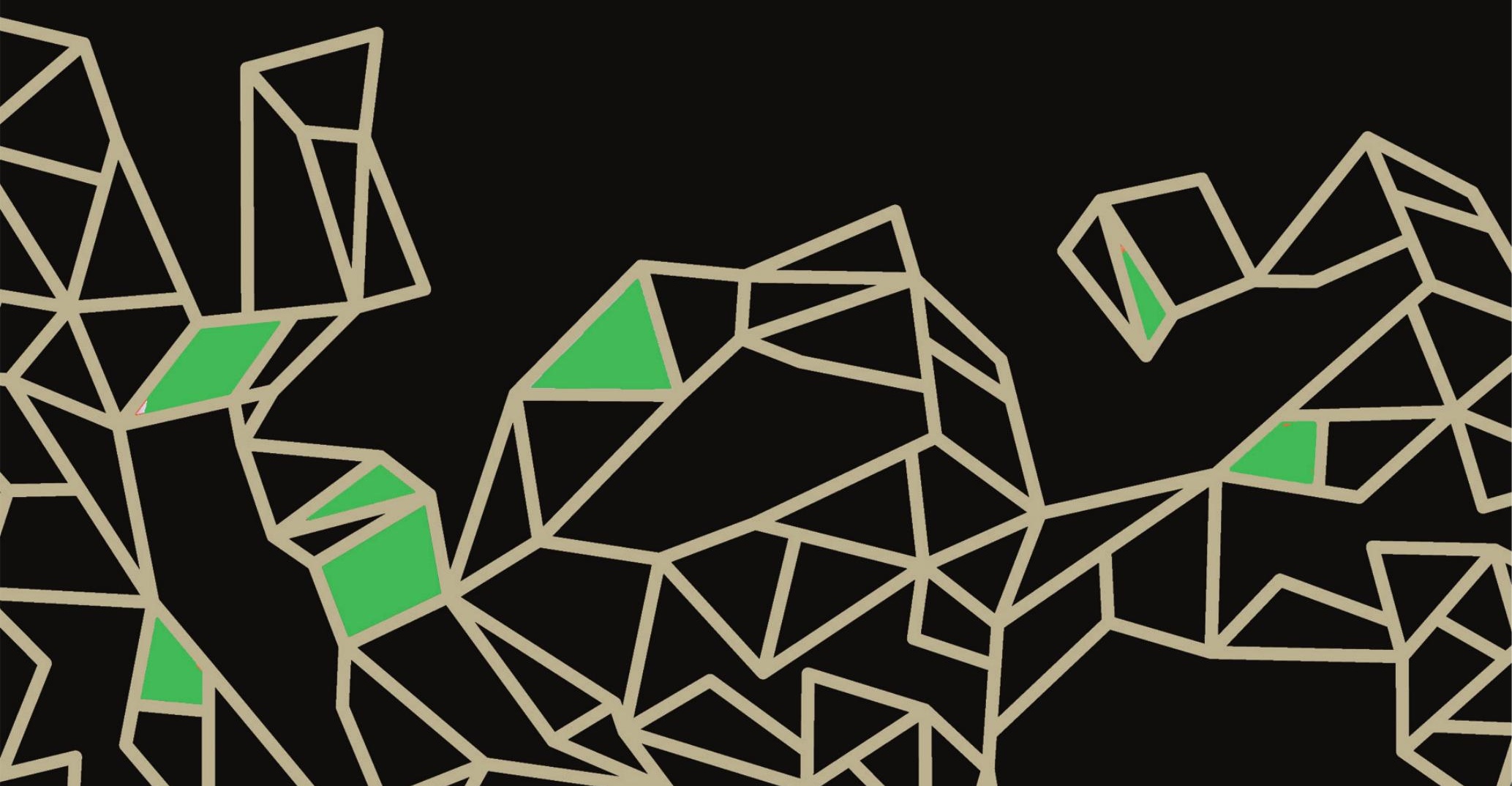




\section{Resumo}

Este ensaio coloca em tela questões relacionadas às dificuldades de interlocução dos sujeitos contemporâneos evidenciadas no espetáculo Branco: o cheiro do lírio e do formol. Considera que a impossibilidade do diálogo aparece em três esferas distintas: o núcleo familiar, o dramaturgo-diretor e a recepção do espetáculo. Dessa forma, destaca construções discursivas que não permitem o acesso a alguma verdade, tornando-se meros semblantes que falseiam a realidade. Outrossim, o racismo constitui-se coluna de sustentação da opressão patriarcal e da exploração capitalista.

Palavras-chave: Branco: o cheiro do lírio e do formol, Teatro brasileiro contemporâneo, Racismo, Branquitude.

\section{Abstract}

This essay focus on questions related to dialogue difficulties of contemporary subjects revealed in Branco: o cheiro do lírio e do formol. It considers that the impossibility of dialogue emerges in three different spheres: family center, playwright-director, and the reception of the show. Therefore, it highlights discourse constructions that do not allow access to any truth, turning themselves into twisting reality ordinary semblants. Thus, racism represents a support column of patriarchal oppression and capitalist exploitation.

Keywords: Branco: o cheiro do lírio e do formol, Brazilian contemporary theater, Racism, Whiteness.

SASPORTAS - O teatro da revolução branca chegou ao fim. Nós o condenamos à morte, Victor Debuisson. Porque sua pela é branca. Porque seus pensamentos são brancos debaixo da sua pele branca. Porque os seus olhos viram a beleza das nossas irmãs. Porque suas mãos tocaram a nudez das nossas irmãs. Porque os seus pensamentos comeram os seios delas, seus corpos, seus sexos. Porque você é um proprietário, um senhor. Por isso o condenamos à morte, Victor Debuisson. Que as cobras comam a sua merda, os crocodilos, a sua bunda, as piranhas, os seus testículos. [Debuisson grita] A desgraça de vocês é que não conseguem morrer. Por isso matam tudo que está ao redor. 
No período letivo de 1996-97, Jacques-Alain Miller e Éric Laurent proferiram o seminário O Outro que não existe e seus comitês de ética no Departamento de Psicanálise da Universidade de Paris VIII. Segundo eles, a contemporaneidade tornou-se uma psicose coletiva e autista, na qual os sujeitos não conseguem sustentar laços. Miller (2002) afirma que hoje o saber não passa de um semblante, de uma forma sofisticada de se esconder o real por meio de discursos e verdades forjadas linguisticamente. Dessa forma, o semblante "consiste em fazer crer que há algo ali onde não há" (p. 18). Não se trata de mentira, mas sim de usar a própria realidade para ocultar e dissimular. Para esse sujeito, o outro não existe, pois não há verdade além de suas convicções. As trocas e o convívio só interessam se configurarem uma extensão narcísica do Eu. Enclausurado em seu próprio gozo, o sujeito monologa.

Esse alheamento do sujeito em relação ao outro é camuflado por formas contemporâneas de militância e engajamento político. Para os sujeitos da contemporaneidade, convêm narrativas forjadas que naturalizam o que é cultural. $\mathrm{O}$ corpo e seus atributos físicos emergem como realidade última, inquestionável trampolim para seu balbuciar repetitivo de palavras de ordem e ideias pré-fabricadas. Essa visão é confrontada por Jacques Lacan que, ressoando a ideia artaudiana de um corpo sem órgãos, desvincula o biológico do natural. Outrossim, se para Michel Foucault não há verdade que não seja discursiva, Judith Butler mostra as dificuldades de se construir uma ética que absorva as singularidades, em outras palavras, um discurso que não seja semblante. Nessa linha, discursar sobre racismo, negritude ou branquitude é sempre falar de construções discursivas que legitimam práticas de opressão. O corpo negro e o corpo branco inserem-se de maneiras distintas nos laços sociais não por algum atributo inato mas em decorrência de investimentos simbólicos e imaginários forjados ao longo da história. Na contemporaneidade, há uma demanda para que dispositivos de dominação relacionados ao corpo negro historicamente construídos sejam desativados. Não por acaso, quando militantes do movimento negro se manifestaram contra o espetáculo Exhibit $B$ na França, justificaram a ação não como censura mas sim como descolonização do imaginário. Paradoxalmente, na medida que aumentam as reivindicações por reparação de danos e compensações históricas, surgem 
novos conflitos pois os sujeitos coletivos estão, eles mesmos, mergulhados no bojo da ideologia dominante da qual supostamente pretendem se libertar.

É com essas chaves de leitura que este ensaio pretende compreender a trajetória do espetáculo Branco: o cheiro do lírio e do formol, de Alexandre Dal Farra e Janaina Leite. A peça busca uma verdade que não seja semblante e, a partir de diálogos com membros de uma família cujo patriarca havia falecido recentemente, evidencia contradições profundas nas quais o racismo e as distinções de classe revelam-se como dispositivos da dominação patriarcal. Os diálogos são intercalados com a voz de um dramaturgo-diretor que sofre e goza ao se confrontar com sua condição de dominador, branco, heterossexual, privilegiado.

O texto de Alexandre Dal Farra desmorona alicerces discursivos presentes em falas aparentemente emancipatórias. Dessa forma, Branco alinha-se a outras obras do autor, a exemplo da trilogia Abnegação, que trata das ações da esquerda quando chega ao poder. Em Abnegação I e Abnegação II O começo do fim, a referência é o Partido dos Trabalhadores, em especial o episódio do assassinato do prefeito de Santo André, Celso Daniel, em 2002. Em Abnegação III - Restos, o olhar é deslocado para contextos familiares, colocando em evidência o poder diluído em sua microfísica. Abnegação III e Branco compartilham de um desencantamento mais amplo do que o apontado nas duas primeiras peças da trilogia, sem apresentar nenhuma saída possível a não ser a apatia de suas personagens. A desilusão converte-se em apatia ou cinismo; as personagens voltam-se para preocupações ordinárias, fecham-se em redomas que impedem a interlocução com o outro. Machismo, homofobia e racismo surgem na obra de Dal Farra (2017b) como colunas de sustentação da opressão patriarcal e da exploração capitalista, gerando uma "desigualdade [que] estrutura a própria realidade" (p. 22), mas cuja força motriz é a exploração capitalista.

ATOR - VAI SE FUDER SEU BRANCO DE MERDA EU ACHO QUE NADA DO QUE NÓS ESTAMOS FAZENDO REPRESENTE OS REAIS PROBLEMAS DAS NOSSAS VIDAS ATUALMENTE O CAPITALISMO CHEGOU A UM NÍVEL DE DESENVOLVIMENTO QUE NÃO TEM MAIS VOLTA NÃO TEM MAIS NADA SÓ DESTRUIÇÃO E MORTE DESTRUIÇÃO E MORTE E SEXO E NADA ALÉM DISSO MAS NÓS SOMOS SÓ 
PEÇAS DESSA PORRA E VAMOS FICAR AQUI FAZENDO A NOSSA PARTE ENTÃO FODA-SE VAI SE FUDER VAI SE FUDER EU NÃO SOU OBRIGADO A NADA EU NÃO GOSTO DE NADA DISSO VOCÊS TODOS TAMBÉM PENSAM ASSIM ME RESPONDAM POR FAVOR AH VOCÊ ESTÁ QUERENDO DIZER ALGUMA COISA MAS NÃO DÁ PARA ESCUTAR EU ODEIO QUANDO VOCÊ FAZ ISSO POR FAVOR PARE AGORA EU ENTENDI MELHOR CALMA CALMA NÃO FAÇA ASSIM ESPERA EU ESTOU SOFRENDO VOCÊS NÃO SABEM COMO EU SOFRO CARALHO CARALHO CARALHO PORRA QUE MERDA É ESSA??? É ISSO QUE EU VOU FICAR FAZENDO???

DIRETOR - Essa última parte não estava no texto. Tira essa parte. Desde o "caralho caralho", não está no texto. Segue a partir de onde parou. (Ibid., p. 11, maiúsculas no original)

A morte do pai, nesse contexto, remete ao mal-estar fundador da civilização apresentado por Freud em Totem e Tabu, consequência do assassinato do pai da horda primitiva. É preciso que esse pai seja assassinado para que surja outro ordenamento social com novas configurações dos laços entre os sujeitos. A voz do dramaturgo diz na última fala de Branco:

\footnotetext{
Porque em algum momento eu entendi que nessa peça alguém precisava morrer. Alguém que fosse uma parte de mim mesmo. Tentei achar que esse alguém poderia ser simbolizado pelo meu pai. Mas essa morte não era de mais ninguém. Ela não podia recair sobre mais ninguém além de mim mesmo. Aquele cadáver era meu. Só podia ser meu. Só podia ser eu. (DAL FARRA, 2017b, p. 43)
}

Não é um teatro psicológico, característica falsamente atribuída por quem reduziu a peça a uma expiação da culpa ou a um conflito existencial. Se assim fosse, seria um traço narcisista, ausente na dramaturgia de Dal Farra. O pai, figura que insere os sujeitos na ordem simbólica da linguagem e das leis, é colocado para fora. Sem os limites da lei, os sujeitos perdem a direção. A morte do pai em Branco não é um componente dramático, mas sim a manifestação de uma foraclusão generalizada do Nome-do-Pai, um delírio psicótico coletivo no qual as reações de parte do público a Branco são uma expressão candente.

Ainda que não negue o mal sofridos pelos negros, esse não parece ser um tema central em Branco. Embora não negue o racismo e o privilégio 
branco, a peça coloca em cena o opressor, caracterizando-o com nuances não maniqueístas. Dessa forma, evidencia contradições e impasses de sujeitos mergulhados em uma modernidade que aprofundou as desigualdades e fragmentou os discursos. Assim como no espetáculo Conversas com meu pai, outro trabalho do autor, os comentários do dramaturgo-diretor que intercalam os diálogos da família revelam a impossibilidade de coerência entre os discursos ${ }^{1}$, pois a comunicação com o outro não depende somente de vontades individuais, visto que nascemos sob o jugo da dominação patriarcal e capitalista:

Que nem outro dia, quando eu parei em um farol, e vi uma família descendo de um carro grande, na frente de um restaurante, descendo de uma Range Rover, ou algo do tipo. Um pai, uma mãe e dois filhos. Eles eram negros. Tinham dois filhos pequenos, dois bebês mesmo, que estavam deitados em um carrinho especial, duplo. O casal estava muito bem vestido. Aquela família de negros estava entrando em uma pizzaria chique, em Higienópolis. Eu vi aquela cena e fiquei naturalmente feliz. Eu me senti leve, senti que o mundo estava melhorando, me senti bem, mesmo. Mas em seguida, quando abriu o farol e eu segui com o meu carro, eu pensei: eu não deveria ter nem notado essa família. (DAL FARRA, 2017b, p. 21-22)

Desde sua primeira interrupção, o dramaturgo hesita, tateia, parece não saber avaliar em qual terreno está pisando:

Racismo: Algum dia no primeiro semestre de 2016 comecei a trabalhar em um texto onde eu achei que poderia falar sobre racismo. Achei que não bastava ficar quieto. O movimento de afirmação do seu lugar de fala, por parte do negro, não podia ser usado pelos brancos como justificativa para ficarmos confortavelmente quietos, usufruindo do racismo que estrutura e dá condições de existência para esse nosso próprio silêncio. Nós também precisávamos tentar olhar para isso. E escutar, no caso, também era algo de ativo. Algo que o branco precisava construir. Construir um tipo de lugar de escuta, e para isso a minha experiência em relação ao racismo também deveria ser uma experiência, a minha crueldade

1 A esse respeito, Schenker (2017) destaca: "Em Branco: o cheiro do lírio e do formol, o inacabado se impõe como escolha e não como insuficiência. Não é uma proposta inédita, tendo em vista que marcou muitas montagens nas últimas décadas, mas essa constatação não diminui a pulsação de um teatro como o de Dal Farra, no qual o rascunho é a arte final." 
com a minha própria operação do racismo estrutural devia ter alguma validade. Eu tinha tido essa ideia. (DAL FARRA, 2017b, p. 4)

A família, ao contrário, atém-se a conversar, sem entusiasmo, sobre trivialidades: a compra de um carro, o perigo das drogas, a comida, o passeio no shopping. A violência para eles é ordinária e sórdida. O medo que sentem do outro - negro, desconhecido - é um temor trágico, incontornável. Por isso mesmo, aceitável. Relatos de agressão são banalizados para manter em funcionamento suas conversas sem fim, vazias de conteúdo.

MENINO - Uma vez também um policial comeu o meu cu à força em um matinho. Aqui perto de casa.

MULHER - o mundo é um lugar injusto. (DAL FARRA, 2017b, p. 17)

MEU PRIMO - Eu estava chegando em casa de noite. Tinha um cara estranho lá. Dei uma volta no quarteirão com o carro. Liguei para o segurança da rua. Fiquei esperando na esquina com o farol desligado. $O$ segurança chegou, deu uns gritos, e o cara respondeu umas coisas, mas o segurança mostrou para ele a arma, e aí o cara foi embora na mesma hora. Eles se entendem muito bem entre si. Sabem como lidar uns com os outros. Os bandidos e os seguranças. São dois lados da mesma moeda! (DAL FARRA, 2017b, p. 20)

A família revela-se um ajuntamento de pessoas, sem convívio ou partiIhas significativas entre elas. Fechados em si mesmos, não há um outro capaz de estabelecer alguma troca. Mantêm-se próximos por questões convencionais: a tradição, o sustento material, os laços sanguíneos revestidos imaginariamente de ilusão de pertencimento. São aturditos, neologismo proposto por Lacan (2003) relacionando o estado aturdido com a interdição do dizer. São personagens constituídos pela falência do Aufklärung, a ilusão iluminista de autonomia dos sujeitos que se tornou outro projeto fracassado da modernidade. $\mathrm{O}$ diretor, por sua vez, tenta romper esse processo, mas sucumbe.

Eu precisaria sempre ter alguém para perguntar, um outro, um negro por exemplo, para que eu pudesse medir essas coisas: "se eu digo isso, estou te ofendendo? Isso é ofensivo? Alguma coisa do que eu acabei de dizer é ofensiva??" Eu preciso que alguém venha até mim, ditatorialmente, de maneira certeira e clara, e violenta, e me avise sempre que eu 
disser algo de ruim, algo que diminua essa outra pessoa!!! Esse contato com o outro precisa se dar dessa forma, eu preciso ser fiscalizado, eu não confio em nada do que eu mesmo tenho a dizer, eu não sei!!! Eu sempre sou suspeito de fazer alguma coisa escrota sem perceber. $\mathrm{O}$ suspeito não era o cara que estava rondando a sua casa, o suspeito era você, que estava olhando o cara rondar a sua casa!!! Você estava correndo todos os riscos de tomar uma atitude opressora, e aí, como você é um branco heterossexual que não dá a mínima para esse tipo de questão, você foi lá e fez exatamente isso, tachou o cara, mandou o outro escorraçar ele! (DAL FARRA, 2017b, p. 18)

Sufocado pelos discursos e por uma multiplicidade de vozes, o diretor reconhece a impossibilidade do diálogo:

Nós, brancos, heterossexuais, homens de classe média, precisamos tomar o cuidado máximo com o que nós dizemos porque tudo o que nós dizemos na verdade, simplesmente por ser dito por nós, se configura como um tipo de ofensa, como um discurso de dominação, essa é a verdade! Então é melhor a gente simplesmente ficar quieto e não dizer mais nada, sobre assunto nenhum, quanto mais em relação a esse tipo de problema que claramente não é nosso, como racismo, homofobia, machismo, etc. (DAL FARRA, 2017b, p. 23)

$\mathrm{O}$ alheamento que as personagens da família mantêm entre si e a dificuldade do dramaturgo em dar destino a suas angústias revelam a incapacidade de comunicação. Mulher, Homem e Menino isolam-se ignorando o outro. Já o dramaturgo tenta o diálogo, mas é solapado por uma multiplicidade de vozes (a sua própria, a dos movimentos contemporâneos que reivindicam uma correção inalcançável da linguagem e do lugar de fala, a da militância negra, a dos racistas e a dos negros). Saindo da dramaturgia e verificando a recepção de Branco, constata-se que essa incomunicabilidade é generalizada para além do texto, para além do espetáculo.

\section{A recepção de Branco}

O ensaio de Luiz Fernando Ramos sobre Branco para o catálogo da Mostra Internacional de Teatro de São Paulo (MITsp) aborda duas versões prévias de Dal Farra até consolidar-se na terceira, apresentada na estreia. Até 
o final da segunda temporada, no Centro Cultural São Paulo, o texto sofreu outras modificações que revelam, em larga medida, a tentativa de abarcar as críticas e as contribuições. Esse esforço, porém, indicou novas impossibilidades de diálogo, apesar de Branco ser um espetáculo bem recebido pela crítica teatral:

$\mathrm{Na}$ ágora reinventada, é preciso opinar (sempre), é preciso posicionar-se, é mister dizer alguma coisa porque ficar em silêncio equivale a não existir. O ópio da vez é a crença de que a palavra está com todos, de que ter direito a voz significa ter direito a poder. (MENEZES, 2017)

Os conflitos na esfera profissional (a concepção do texto) e no âmbito pessoal (o vínculo pai/filho) fazem com que os atores se conscientizem de seus comprometimentos com uma determinada problemática (no caso, o racismo) e com elos afetivos obstruídos. (SCHENKER, 2017)

No entanto, as reações contrárias foram contundentes e revelam, em larga medida, os impasses e paradoxos dos quais a própria peça trata:

O fio condutor da narrativa da mimese da família sulista estadunidense que entre falas e vômitos pouco tem a fazer para apagar os rastros da sua decadência é desviado para as crises de consciência do intelectual iluminista dramaturgo que não se conforma com seu racismo nem com o seu privilégio. (OLIVEIRA, 2017)

O grupo branco mostra algumas das críticas que receberam dos artistas provocadores negros sobre a sua tentativa - preconceituosa - de representar o negro e a questão do "lugar da fala". Afinal, como alguém pode abordar a dor ou a realidade que o outro sente/vive, sem experimentá-la na pele? (SP ESCOLA DE TEATRO, 2017)

Se Alexandre Dal Farra e a equipe de "Branco", cuja direção é assinada também pela atriz Janaina Leite, em cena ao lado dos atores André Capuano e Clayton Mariano, queriam realmente discutir o racismo, que começassem por abrir mão do privilégio de estar na grande de um festival tão renomado com uma peça tão confusa e problemática e cedessem o lugar (e o cachê) a um dos grupos negros que discutam (sic) com profundidade o racismo brasileiro e tanto lutam por um lugar de fala e representatividade. (ARCANJO, 2017) 
E nesse sentido vejo o espetáculo como um desserviço, inclusive usando um espaço que seria, ao meu ver, mais legítimo a uma obra do segmento negro com questões negras e minimamente com atores negros, uma galera que precisa todos os días afirmar que existe, que resiste para fazer arte e simplesmente viver. (SANTOS, 2017)

As demonstrações de repúdio a Branco esvaziam o sentido da ideia de lugar de fala. Esse conceito, oriundo de debates acadêmicos, apareceu pela primeira vez nos anos 1980 nos trabalhos de Linda Alcoff e Gayatri Spivak. Grosso modo, refere-se à ideia de que determinadas condições do sujeito da enunciação produzem diferentes efeitos de verdade. Uma compreensão equivocada, que transforma o lugar de fala em exclusividade para certos sujeitos, vem sendo disseminada. Para aqueles que sustentam essa posição, Branco foi erigido como expressão de privilégios. Não poderiam brancos, por serem brancos, falarem de racismo. Seguindo essa linha de argumentação, houve reclamações sobre a utilização de recursos públicos que teriam sido aplicados no projeto, em detrimento de iniciativas de artistas negros.

\section{Contexto}

O racismo aparecia como um dos eixos curatoriais da $4^{\text {a }}$ MITsp. Além de Branco, compunham esse núcleo os espetáculos Black off, da diretora e performer sul-africana Ntando Cele, e A missão em fragmentos: 12 cenas de descolonização em legítima defesa, com direção de Eugênio Lima. A programação da mostra também inclui o seminário Discursos sobre o não dito: racismo e a descolonização do pensamento, além de encontros entre artistas e pesquisadores que englobaram temas como o lugar de fala, o feminismo negro e as ideias de "negritude" e "branquitude".

No ano anterior, a questão racial já ocupava um espaço considerável na grade da programação. Em 2016, foram apresentados os espetáculos Cidade Vodu, direção de José Fernando de Azevedo, com a Companhia Teatro de Narradores; Revolting music - Inventário das canções de protesto que libertaram a África do Sul, criação, dramaturgia, direção musical e atuação do sul-africano Neo Muyanga; e o espetáculo de dança $A$ carga, coreografia e performance do congolês Faustin Linyekula. Ainda nesse ano, 100\% São 
Paulo, do coletivo Rimini Protokoll, provocou algumas manifestações que o acusavam de racismo. Tal espetáculo é um experimento cênico realizado no âmbito do projeto 100\% City, já apresentado em várias cidades (entre elas Berlim, Zurique, Londres, Paris, Copenhague, San Diego, Melbourne e Tóquio); o projeto utiliza dados estatísticos oficiais para selecionar pessoas que, no palco, irão responder a perguntas e, assim, compor uma espécie de amostra quantitativa sobre temas polêmicos como segurança, aborto, sexualidade e política. Em São Paulo, foram registradas queixas do público devido à pouca presença de negros no espetáculo.

Essa reclamação, porém, foi de impacto menor que o provocado quando a MITsp anunciou a vinda do espetáculo Exhibit $B$, do sul-africano Brett Bailey, para a terceira edição da mostra. $O$ trabalho de Bailey utiliza atores negros para recriar fotografias reais de violência racial e seguiu uma longa carreira desde sua estreia - até que começaram a surgir manifestações contrárias à proposta de Bailey, acusado de racismo. Em São Paulo, o espetáculo seria apresentado no Teatro da USP, mas ficou de fora da programação da mostra devido ao contingenciamento orçamentário provocado pela diminuição de verbas de patrocínio. A partir desse cancelamento, foram disseminadas várias interpretações, levando algumas pessoas a acreditar que os organizadores da MITsp sucumbiram às reivindicações do movimento negro ou que os patrocinadores haviam deliberadamente cortado o orçamento por serem contrários à peça. Os atores já selecionados para participar da montagem brasileira de Exhibit $B$ formaram um novo grupo que, sob a direção de Eugênio Lima, realizou em 2016 a performance Em legítima defesa e em 2017 o espetáculo A Missão em fragmentos.

Essas manifestações inserem-se no bojo de uma história anterior, cujo marco inicial pode ser estabelecido com o cancelamento da apresentação do espetáculo A mulher do trem, da companhia Os Fofos Encenam, no Itaú Cultural de São Paulo, em maio de 2015. A utilização do recurso conhecido como blackface, no qual atores brancos pintam seus rostos de preto para caracterizar personagens negros, geralmente cômicos, suscitou um amplo debate. Somam-se, nessa série, controvérsias envolvendo o espetáculo Entrevista com Stela do Patrocínio e o filme Vazante, de Daniela Thomas. 
Não por acaso, essas situações coincidem com um momento de expansão do teatro negro no Brasil, haja vista a consagração de grupos como Coletivo Negro, Capulanas e Os Crespos. Soma-se a isso o crescente número de alunos negros nas escolas de teatro, fenômeno que pode ser observado na SP Escola de Teatro, no Departamento de Artes Cênicas da ECA-USP e na Escola de Arte Dramática. Essa expansão, ainda que incipiente, tem fortalecido o protagonismo negro no campo teatral.

\section{Falar sobre isso}

Toda cultura é construída por contrastes. Ações antes isoladas, como o Teatro Experimental do Negro nos anos 1940, são agora confrontadas com iniciativas potentes e que colocam em xeque pilares racistas e machistas que estruturaram o campo teatral brasileiro. Ao mesmo tempo, encaramos a dificuldade de desarmar os mecanismos de dominação e estabelecer diálogos realmente emancipatórios. Os discursos convertidos em semblante geram dificuldades de fala e de interlocução.

Em quatro momentos do texto, o dramaturgo-diretor de Branco refere-se à branquitude como "falar sobre isso". O isso, a coisa, anestesia parcialmente o desconforto da situação. Ao eleger como tema a branquitude, Branco inova ao deslocar o eixo da discussão sobre o racismo. Se for possível haver algum entendimento entre brancos e negros, não basta denunciar a violência e o preconceito. Assim como o racismo, a branquitude também é construída culturalmente, gerando corpos que, por serem brancos, têm passe livre. "Ocupar a branquitude sempre foi um privilégio", diz a personagem Bianca White de Black off, "você pode ser qualquer pessoa e andar por aí sem que ninguém te pergunte nada.. Branco desnaturaliza essa condição. Ou, conforme Luciana Romagnolli (2017), o ser branco "precisa ser demarcado para que não se confunda com o natural ou a norma".

Slavoj Žižek (2012) aponta para o fato que falar sobre racismo, homofobia e misoginia pode servir para não falar sobre capitalismo. Essa afirmação não deve ser entendida como um menosprezo por essas questões, pois, apesar de serem demandas libertárias, são também mantenedoras do status quo. Não se trata de um erro, mas sim de condições intrínsecas a sua gênese. 
Branco evidencia um momento no qual, diante da impossibilidade do diálogo, o entendimento torna-se impossível e inviável.

Os múltiplos impasses apontados neste ensaio, agrupados em três níveis (as personagens, o dramaturgo-diretor e a recepção), apresentam um circuito fechado no qual qualquer tentativa de interlocução fracassa. "Será que estamos prontos, enquanto sociedade, para fazer algo juntos? Essa pergunta não é retórica", diz o dramaturgo-diretor da peça (DAL FARRA, 2017, p. 24). Ainda não sabemos a resposta.

\section{Referências bibliográficas}

ARCANJO, M. Crítica: Branco é um espetáculo racista confesso e sem remorso. Blog do Arcanjo, São Paulo, 20 mar. 2017. Disponível em: <https://goo.gl/XVZFfE>. Acesso em: 13 out. 2017.

BUTLER, J. Relatar a si mesmo: crítica da violência ética. Belo Horizonte: Autêntica, 2015.

DAL FARRA, A. Abnegação. Belo Horizonte: Javali, 2017a.

Branco: o cheiro do lírio e do formol. 2017b. Inédito.

Manual da destruição. São Paulo: Hedra, 2012.

FIORATTI, G. Antes de cancelar peça acusada de racismo, mostra propôs troca a autor. Folha de S.Paulo, São Paulo, 19 fev. 2017. Disponível em: <https://goo.gl/ 3G5jAT>. Acesso em: 14 out. 2017.

FOUCAULT, M. Subjetividade e verdade. São Paulo: Martins Fontes, 2016.

FREUD, Sigmund. Totem e tabu. São Paulo: Penguim/Cia. das Letras, 2015.

LACAN, J. O aturdito. In: . Outros escritos. Rio de Janeiro: Jorge Zahar, 2003. p. 448-496.

MENEZES, M. E. Peça "Branco: o cheiro do lírio e do formol" não pode ser reduzida a passionalidades. O Estado de São Paulo, São Paulo, 15 maio 2017. Disponível em: <https://goo.gl/XjZwng>. Acesso em: 10 out. 2017.

MILLER, J.-A. La categoría de semblante. In: De la naturaleza de los semblantes. Buenos Aires: Paidós, 2002.

Piezas sueltas. Buenos Aires: Paidós, 2013.

MILLER, J.-A.; LAURTENT, E. El otro que no existe y sus comités de ética. Buenos Aires: Paidós, 2005.

MÜLLER, H. A missão: lembranças de uma revolução. São Paulo: N-1 Edições, 2016. 
NUNES, L. Sul-africana Ntando Cele revira o racismo em peça. Diário da Região, São José do Rio Preto, 14 mar. 2017. Disponível em: <https://goo.gl/6q1fpW>. Acesso em: 10 out. 2017.

OLIVEIRA, D. Crítica: O formol e o teatro do opressor na peça Branco. Blog do Arcanjo, São Paulo, 2 maio 2017. Disponível em: <https://goo.gl/G4KNfA>. Acesso em: 13 out. 2017.

RAMOS, L. F. O racismo de cada um e os riscos de enfrentá-lo. cartografias.MITsp, São Paulo, n. 4, p. 84-92, 2017.

RIBEIRO, S. Não estar é a única forma de presença de negros - e a culpa não é nossa. Blog do Arcanjo, São Paulo, 9 maio 2017. Disponível em: <https://goo.gl/ rRd7nf>. Acesso em: 13 out. 2017.

ROMAGNOLLI, L. Branca é a ausência, negra é a exclusão. Horizonte da Cena, Belo Horizonte, 20 mar. 2017. Disponível em: <https://goo.gl/FjvR71>. Acesso em: 10 out. 2017.

SANTOS, A. B. Crítica: Lírio e formol, espetáculo Branco vomita branco e é um desserviço. Blog do Arcanjo, São Paulo, 6 maio 2017. Disponível em: <https://goo.gl/ EdUZ5d>. Acesso em: 13 out. 2017.

SCHENKER, D. A perpetuação da ausência. Teatrojornal, Rio de Janeiro, 19 mar. 2017. Disponível em: <https://goo.gl/Sa5EUG>. Acesso em: 10 out. 2017.

SP ESCOLA DE TEATRO. Polêmico "Branco: o cheiro do lírio e do formol" volta ao CCSP. Catraca Livre, São Paulo, 6 abr. 2017. Disponível em: <https://goo.gl/ BV5B85>. Acesso em: 10 out. 2017.

SPIVAK, G. C. Pode o subalterno falar? Belo Horizonte: Editora UFMG, 2010.

ŽIŽEK, S. Vivendo no fim dos tempos. São Paulo: Boitempo, 2012.

Recebido em 21/10/2017

Aprovado em 23/10/2017

Publicado em 26/12/2017 